\title{
A Study of the Impact of Instruction Style on the Quality of Postgraduate Education
}

\author{
Guihua Liu ${ }^{1}$ and Yang Zhou, ${ }^{1, *}$ \\ ${ }^{1}$ School of Public Administration, Southwest-Jiaotong University, Chengdu, SiChuan 610031, China \\ *Corresponding author.Email: zy992436@163.com
}

\begin{abstract}
Instructing is a key factor in the quality of postgraduate education, and there are many different instruction styles. The purpose of this paper is to investigate the relationship between instruction styles and the quality of postgraduate education through an empirical investigation, so as to explore the extent of instruction style to postgraduate education quality and which one can mostly affect postgraduate quality among supportive, controlling, permissive, and relational. This study empirically analysed the relationship between instruction style and postgraduate instruction quality based on the survey data of full-time academic master's students in a university in southwest China. It was found that the controlling and permissive instruction styles did not have a significant impact on the improvement of postgraduate education quality; the supportive and the relational instruction styles had a more significant positive impact on postgraduate instruction quality.
\end{abstract}

Keywords: graduate education, mentor guidance, instruction style, instruction quality

\section{INTRODUCTION}

At the present stage of postgraduate education, the supervisor system is implemented, and the supervisor is a "significant other" in the academic journey of postgraduates.[1] Supervisors have an all-round influence on the research guidance and future career development of postgraduates during their studies, and it is of great practical significance to analyse the influence of supervisors on the development of postgraduates' abilities.[2] Research shows that the satisfaction of postgraduates with their mentors is related to the instruction style of their mentors, [3]while the learning acquisition of postgraduates in China is generally at an intermediate level.[4] So, does the instruction style of mentors affect the quality of postgraduates' instruction? What is the role of different instruction styles in improving the quality of postgraduate instruction? This study takes full-time academic postgraduates in a university in southwest China as the research objects and uses survey data to conduct an empirical analysis in order to explore the influence of instruction styles on the quality of postgraduate training and to provide reference to improve the quality of postgraduates' education. [5]

\section{LITERATURE REVIEW AND RESEARCH HYPOTHESIS}

It has been shown that instruction style affects the instruction quality of postgraduates, especially the research innovation ability, Chi Liquan pointed out that instruction style plays a key role in shaping and cultivating the innovation quality of postgraduates, Luo et al. argued that the development of postgraduates' academic ability is deeply affected by instruction style, instruction content, and efficiency in the process of instruction-student interaction. [6]

Instruction styles of individual mentors are diverse, and foreign scholars generally use management square theory and other research methods to study instruction styles, for example, Gatfield constructed four types of instruction styles based on management square theory: "laissezfaire", "pastoral", "directive" and "contractual".[7]Domestic scholars such as Pan Binru classifies instruction styles into mentor-friend, authority, club and permissive, and believes that mentor-friend style is more conducive to improving the research ability of postgraduates. [8]

Combining the findings of scholarly research and instruction practices, this study classifies instruction styles into four categories: supportive, controlling, permissive, and relational. Based on the existing research base and consideration of the availability of information, the following assumptions are made in this paper.

Hypothesis 1: There is a positive relationship between mentor supportive instruction style and postgraduate instruction quality.

Hypothesis 2: There is a positive relationship between mentor-controlled instruction style and postgraduate instruction quality.

Hypothesis 3: There is a positive relationship between permissive instruction style and postgraduate instruction quality.

Hypothesis 4: There is a positive relationship between mentor relational instruction style and postgraduate instruction quality. 


\section{DESIGN OF THE QUESTIONNAIRE}

\subsection{Test of the Questionnaire}

This study uses the questionnaire method as the main research method, and the research subjects come from a 211 university in the southwest of China. The topics of the instruction situation and the quality of postgraduate instruction in this questionnaire are mainly derived from the analysis of interview data, literature research and textual data, this questionnaire has good content validity. Meanwhile, the $\mathrm{KMO}$ value of the predicted sample is 0.719 , which is an adequate sample size, and the test of sphericity, $\mathrm{P}=0.000<0.05$, is consistent with the test of sphericity. Combining the two indicators allowed for a factor analysis. Therefore, from content validity to construct validity, it can be concluded that the validity of this questionnaire is good. After the factor analysis, the reliability test between the dimensions of the scale and the total scale is to be continued. In the reliability analysis of this questionnaire, the alpha coefficient was used to measure. The validity questionnaire was imported into SPSS 24.0 software data analysis, where the value of the alpha coefficient was 0.524 , with a certain level of reliability.

\subsection{Distribution of Questionnaires and Sample Distribution}

This study was conducted based on the real feelings of postgraduates about their instruction style as the material, and the research goal was to provide help for improving the quality of postgraduate training. The scientificity of the research results is directly influenced by the authenticity and validity of the original materials, and since the target population of this study is full-time academic postgraduates, this survey adopts a combination of purposive sampling and random sampling and is mainly distributed to full-time academic master's students in all departments of the university. A total of 200 questionnaires were distributed, 170 were collected, and 141 were valid. Among the valid questionnaires collected, there were 18 questionnaires in the first year of study, accounting for $10.6 \%$; 42 questionnaires in the second year of study, accounting for $24.7 \%$; and 110 questionnaires in the third year of study, accounting for $64.7 \%$. There were 90 copies for male students and 80 copies for female students.

\section{DATA ANALYSIS}

\subsection{Descriptive Analysis}

\subsubsection{Instruction relationship and instruction style}

In terms of the way in which instruction relationships are established, mentors and students are overwhelmingly chosen in both directions (77.06\%), with few cases assigned by faculty and randomly selected, indicating that mentors and postgraduates are almost equal in the process of mutual search. Drawing on the concepts of supportive and controlling leadership styles proposed by Oldham and Cummings, [9] the article combines literature analysis to classify instruction styles into "controlling," "supportive," "permissive," and "relational", and then explores the relationship between instruction styles and the quality of graduate education.

\subsubsection{Overall quality of postgraduate supervision}

The level of quality of postgraduate instruction was measured using the postgraduate self-assessment method and the variable in the questionnaire was measured using the Likert 5-point scale method. It was found that the overall mean for the variable quality of postgraduate supervision was 2.92, indicating that the quality of postgraduate supervision was average and of a moderate to low level.

\subsection{Hypothesis Testing}

\subsubsection{Correlation analysis}

To understand the correlation between the instruction style of postgraduate mentors and the quality of postgraduate instruction, the Pearson correlation test was used in this study, and the results are shown in Table 1. From the table, we can learn that: the correlation coefficient between supportive instruction style and postgraduate instruction quality is $0.0248(\mathrm{p}=0.001<0.05)$, showing a positive correlation; the probability value of $p>0.05$ for the significance test of the correlation coefficient between controlling instruction style and postgraduate instruction quality, and the correlation is not significant; the probability value of $p>0.05$ for the significance test of the correlation coefficient between permissive instruction style and postgraduate instruction quality. The probability value of $p>0.05$ and the correlation between the two variables is also not significant; the relationship between the two variables 
of relational instruction style and postgraduate instruction quality shows a significant positive correlation with a correlation coefficient of $0.551(\mathrm{p}=0.000<0.05)$, and the relationship is moderately positive with a coefficient of determination $\mathrm{R}^{2}$ equal to 0.304

Table 1 Correlation analysis between the four instruction styles and the quality of postgraduate supervision

\begin{tabular}{|c|c|c|c|c|c|c|}
\hline & & Supportive & $\begin{array}{c}\text { Control } \\
\text { type }\end{array}$ & $\begin{array}{c}\text { Laissez- } \\
\text { faire }\end{array}$ & Relational & $\begin{array}{l}\text { Quality of } \\
\text { guidance }\end{array}$ \\
\hline \multirow{3}{*}{ Supportive } & Pearson related & 1 & 0.155 & $-0.289 * *$ & $0.468 * *$ & $0.248 * *$ \\
\hline & Significance (two-tailed) & & 0.053 & 0.000 & 0.000 & 0.001 \\
\hline & $\mathrm{N}$ & 165 & 157 & 154 & 154 & 163 \\
\hline \multirow{3}{*}{ Control type } & Pearson related & 0.155 & 1 & -0.007 & $0.202 *$ & 0.150 \\
\hline & Significance (two-tailed) & 0.053 & & 0.933 & 0.012 & 0.061 \\
\hline & $\mathrm{N}$ & 157 & 159 & 154 & 154 & 157 \\
\hline \multirow{3}{*}{ Laissez-faire } & Pearson related & $-0.289 * *$ & -0.007 & 1 & -0.078 & 0.033 \\
\hline & Significance (two-tailed) & 0.000 & 0.933 & & 0.334 & 0.684 \\
\hline & $\mathrm{N}$ & 154 & 154 & 157 & 154 & 154 \\
\hline \multirow{3}{*}{ Relational } & Pearson related & $0.468 * *$ & $0.202 *$ & -0.078 & 1 & $0.551 * *$ \\
\hline & Significance (two-tailed) & 0.000 & 0.012 & 0.334 & & 0.000 \\
\hline & $\mathrm{N}$ & 154 & 154 & 154 & 154 & 153 \\
\hline \multirow{3}{*}{$\begin{array}{l}\text { Quality of } \\
\text { tuition }\end{array}$} & Pearson related & $0.248 * *$ & 0.150 & 0.033 & $0.551 * *$ & 1 \\
\hline & Significance (two-tailed) & 0.001 & 0.061 & 0.684 & 0.000 & \\
\hline & $\mathrm{N}$ & 163 & 157 & 154 & 153 & 166 \\
\hline
\end{tabular}

**. Correlation is significant at the 0.01 level (two-tailed). *. Correlation significant at the 0.05 level (two-tailed)

\subsubsection{Summary of hypothesis testing}

A total of four hypotheses are proposed in this paper regarding the relationship between instruction style and postgraduate instruction quality, two of which were tested, that is, (1) There is a positive relationship between mentor supportive instruction style and postgraduate instruction quality; (2) There is a positive relationship between mentor relationship-based instruction style and postgraduate instruction quality.

The two variables of mentor supportive instruction style and postgraduate instruction quality showed a positive correlation, expressed as the more encouragement and support shown by mentors to postgraduates, the higher the quality of postgraduate instruction, but because the coefficient of determination between the two variables was low, it meant that the supportive style of postgraduate mentors could not yet explain most of the increase in postgraduate instruction quality.

Mentor-controlled instruction style showed a nonsignificant correlation with postgraduate instruction quality, indicating that strict supervision and assertiveness of mentors were not associated with a positive impact on enhancing postgraduate instruction quality.

There was a non-significant correlation between mentor permissive instruction style and postgraduate instruction quality, indicating that mentor permissiveness or giving students full freedom to develop is not significantly associated with improving postgraduate instruction quality. There is a positive correlation between instruction style and postgraduate instruction quality, i.e., mentors regard postgraduates as equal collaborators, train postgraduates in joint research, and advocate a mutually beneficial "contractual relationship",[10] which has a certain contribution to the improvement of postgraduate instruction quality. Moreover, the coefficient of determination between the two variables was 0.304 , indicating that the relational instruction style could explain $30.4 \%$ of the improvement in postgraduate instruction quality.

\section{CONCLUSION}

The instruction style of postgraduates is the core issue that determines the quality of graduate training.[11] A large number of studies have shown that, as the "first responsible person" for master's degree students,[12] the mentor's guidance has a positive effect on the quality of postgraduates' education and is extremely important for the development of postgraduates' research ability. This study empirically analysed the relationship between instruction style and postgraduate instruction quality based on the survey data of full-time academic master's students in a university in southwest China. This study on the relationship between instruction style and postgraduate instruction quality is only a starting point, and there is still much room for expansion and improvement. On the one hand, this study only selected a full-time academic master's degree from a university in southwest China as a sample, and the sample selection is limited and cannot present the whole picture of postgraduate guidance, and the sample is not representative enough. On the other hand, the quality of postgraduate guidance is not limited to the guidance of tutors, and the influence of the endogenous learning motivation of postgraduates on the improvement of their learning quality cannot be ignored. Only by combining the 
two can we present the full picture of the problem. Future research in this area should be strengthened.

\section{ACKNOWLEDGMENT}

This work was founded by Postgraduate Teaching Reform Item of South-west Jiaotong University, 2020.

\section{REFERENCES}

[1] BARGARRR, JANEMC. Advisors and advise issues in doctoral education[J]. The journal of higher education, 1983, 54(4):407-432

[2] Li Guanhe, Li Fengliang. An empirical study on the relationship between mentoring and the development of doctoral students' research ability from the perspective of moral education[J]. Degree and Postgraduate Education, 2021(06):67-74. (In Chinese)

[3] Huang Cui-Cui, Yan Su-Zhen. Analysis of Factors Affecting Graduate Students' Satisfaction in Choosing Mentors - An Empirical Study Based on University of $\mathrm{H}[\mathrm{J}]$. Journal of Yangzhou University (Higher Education Research Edition), 2013, 17(1):38-42. (In Chinese)

[4] Ruan Qinshi, Li Chenzhi, Ji Haiji. An empirical study of graduate students' learning acquisition and its influencing factors $[J]$. Educational Exploration So, 2020(03):41-46. (In Chinese)

[5] Zhang Xianhua, Feng Xue, Cui Yuqing. Mentoring style, academic performance and self-satisfaction of professional masters[J]. Journal of Continuing Higher Education, 2021, 34(03):19-26. (In Chinese)
[6] Luo J., Xie Z. W., Mo L. R. Mentor-student interaction model and graduate students' academic competence development-a qualitative analysis based on rooting theory $[\mathrm{J}]$. Degree and Graduate Education, 2021(03):15-20. (In Chinese)

[7] GATFIELDT. An investigation into $\mathrm{PhD}$ supervisory management styles: development of a dynamic conceptual model and its managerial implications[J]. Journal of higher education policy and management, 2005, 27(3):311-325.

[8] Pan Binru. Research on the influence of graduate student training programs on research ability [D]. Guangxi University, 2019. (In Chinese)

[9] Wang X, Gu Jibao, Wu Jianlin. A study on the influence of mentoring style on graduate students' creativity cultivation - the moderating role of students' personal initiative[J]. Degree and Graduate Education, 2013(05):14-17. (In Chinese)

[10] Song, D.F. The three styles of a good mentor [J]. Degree and Graduate Education, 2014(11):15-18. (In Chinese)

[11] Wang P, Wang RF, Zhou Y, Huang ZY, Dai Z. Analysis of the current situation of research on mentoring styles and mentoring methods of graduate students[J]. Journal of Higher Education,2021,7(28):9497. (In Chinese)

[12] Xu Du'an. Research on the influence of mentoring on the research ability of academic master's students [D]. Anhui University of Finance and Economics, 2020. (In Chinese) 